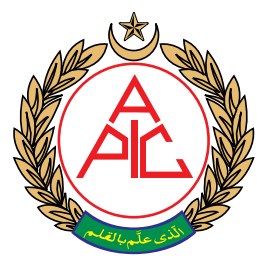

Associate Dean of Faculty, Agha Khan Medical College, Professor of Anesthesiology, the Aga Khan University Hospital, Karachi, Pakistan.

Correspondence: Prof. Faza Hameed Khan, Department of Anesthesiology, Aga Khan University Hospital, Stadium Road, Karachi, Pakistan; 0301-8223899.

E-mail: fazal.hkhan@aku.edu

\section{Perioperative ultrasound; Fashion, luxury or necessity!}

\author{
Fazal Hameed Khan, MCPS, FCPS
}

\begin{abstract}
The technique of ultrasound is not new in medicine. Advancement of the technique, portability of the equipment and the desire of the anesthesiologist to reach to a quick diagnosis has made this an essential tool for today's anesthesiologist. There are many areas during the perioperative period where ultrasound can play an important role in guiding otherwise blind and invasive interventions, diagnosing critical conditions, and assessing for possible anatomic variations that may lead to plan modification. The irrefutable outcome of perioperative use of ultrasound performed by anesthesiologists is increasingly being acknowledged .It has been playing a role in central venous cannulation, epidural space identification, performing peripheral nerve and chronic pain nerve blocks. Transesophageal echocardiography, airway assessment, gastric ultrasound, lung ultrasound and neuro monitoring are some of the newly introduced uses of this modality. As the ultrasound guidance is becoming standard practice of care, anesthesiologists need to develop a thorough understanding of this technology and practical skills by training themselves.
\end{abstract}

Key words: Ultrasound; Perioperative; Interpretation; Training

Editor's Note: This editorial was written by the respected Prof. Fazal H. Khan on our special request to complement a research paper being published in this issue [Soliman AM, Samy MA, Heikal AM, El Ramely MA, Kotb TA. Ultrasound-guided assessment of diaphragmatic thickness as an indicator of successful extubation. Anaesth pain \& intensive care 2019;23(2):178-185]

Citation: Khan FM. Perioperative ultrasound Fashion, luxury or necessity! Anaesth. pain \& intensive care 2019;23(2):115-118
Although the association between living systems and ultrasound has been known and studied since 1920 's, widespread use of ultrasound in clinical medicine started in 1970. Ultrasound refers to the use of sound waves typically from 2 to $15 \mathrm{MHz}$, but in modern probes up to $22 \mathrm{MHz}$, which are above the frequency of those sound waves that can be heard by the human ear. Fluids are main constituents of the soft tissues in the body and mostly responsible for the transmission of sounds in the body. Ultrasound, in particular, is well-suited to support numerous image-guided procedures because system functionality and portability have increased, while costs remain low. Ultrasound usage relies on its verified clinical effectuality, cost effectivity, and practical utility as it enables anesthesiologist to assess intricate exceedingly variable anatomy before needle insertion and rapidly diagnosing life threatening perioperative conditions. The modality also avoids the risks of ionizing radiation. Presentday ultrasound machines are far more compact and conveniently portable, with finer resolution and highly enhanced tissue penetration making it an effective tool for identification and desired intervention in several bodily structures.

The article by Soliman et al. in this issue of Apicare Journal highlights the importance of using ultrasound in predicting successful extubation in mechanically ventilated cancer patients. This is a new area of research in the use of ultrasound in addition to its many other potential applications. We have been using ultrasound for central venous cannulation, epidural space identification, performing peripheral nerve and chronic pain nerve blocks. Transesophageal echocardiography, airway assessment, gastric ultrasound, lung ultrasound and neuro monitoring are some of the newly introduced uses of this modality. ${ }^{1}$ 
The irrefutable outcome of perioperative use of ultrasound performed by anesthesiologists is increasingly being acknowledged. ${ }^{2}$ Ultrasound guided peripheral nerve blockade enabling direct visualization of nerves and encompassing structures and the spread of local anesthetic solution decreases the time taken to perform the block as well as improves block success. The incidence of critical incidents have decreased and this improves patient safety. ${ }^{3}$ As the drug is injected under direct vision therefore the onset of block is faster, quality is better, local anesthetic dosage is reduced and the block duration increases. ${ }^{4}$ There have been similar benefits using this technique in pediatric patients especially during the performance of ilioinguinal nerve blocks. ${ }^{5}$ Ultrasound use helps in identifying inter-spinous spaces, indicates the depth of epidural space with precision hence increases the accuracy and efficacy of lumbar neuraxial blocks. ${ }^{6}$ Ultrasound guidance has been employed for several chronic pain procedures with outcomes quite similar to fluoroscopy guided techniques. Its use during central venous cannulation is safe and less time consuming as the procedure is performed under direct visualization as opposed to traditional landmark techniques. These benefits are supported by research studies for both internal jugular and subclavian vein catheterization. ${ }^{7,8}$

Chances of first attempt successful radial artery cannulation increases with the use of ultrasound. ${ }^{9}$ It is also now commonly used by the anesthesiologists for the detection and management of cardiac pathology and hemodynamic instability during the perioperative period..$^{10}$ Another area in which the anesthesiologist are taking advantage of this modality is for the detection of esophageal intubation especially in difficult conditions. ${ }^{11}$ Its use during percutaneous dilatational tracheostomy decreases procedure related complications. ${ }^{12}$ It has been used in evaluating gastric volume and contents specifically in patients with gastroparesis and during emergency surgeries thus decreasing the risk of pulmonary aspiration. ${ }^{13}$ It can be highly valuable in rapid detection of intraoperative pneumothorax as a result of central venous cannulation. ${ }^{14}$

It is however important to note that in spite of so many advantages claimed for this modality, interpretation of the images depends on the operator experience and practice. If used by the inexperienced operator causing prolonged exposure, high energy emitting ultrasound can cause damage to the tissues.

The practice of perioperative ultrasound may be challenging because many of us, even amongst those who consider themselves experts in transesophageal echocardiography, are not formally trained in ultrasound. The most frequent reason for this unfamiliarity is the lack of time for practice or of role models and experts to learn from and consult with. Recommendations for the practice of focused ultrasound have been published recently, and they address applications, techniques, possible benefits, clinical integration, education, and certification principles in adults and pediatric patients. ${ }^{15}$ It is suggested that a formal training program should allocate time, the means or tools, and the structured activities that will be necessary to ensure that the trainee's future performance will be reliable. There should be practice-venue privileges and medicolegal support, for the perioperative ultrasound physician, in case the diagnosis is wrong and the false positives or false negatives lead to wrong interventions or under diagnosis, respectively. It is also recommended that digital archiving should be in place for quality assurance of the activities. It is possible that ultrasound imaging may become the stethoscope of the future. All of us who are involved in education of future physicians should incorporate the teaching of the foundations and applications of surface ultrasound in our residency programs. We should devote time and effort to include expanded teaching on many of the ultrasound-targeted body areas. The acquisition and maintenance of knowledge requires a "live" curriculum that should be revisited each year and revised as needed. We should keep in mind that the ability to see things on our own is very attractive to a fast-paced, young and not so young generation of trainees and practicing clinicians. However, the implementation of ultrasound in routine clinical practice will require not only high grade precision machines but also a high degree of specific training of anesthesia users. The training in ultrasound techniques in the near future will become an essential part of the core training of every anesthesiologist, just as laparoscopic work is for surgeons.

Anesthesiologists need to develop a thorough understanding of sono anatomy involved and develop clear concepts for both ultrasound technology and skills to visualize several structures intended to be manipulated. The day is not far when ultrasound imaging may become an integral component of anesthesia machine.

As Skubas ${ }^{16}$ commented in a recent editorial, "it is possible that ultrasound imaging may become the stethoscope of the future." One can argue that we have not yet fulfilled the potential of that revered device as illustrated by the lack of widespread adoption of more expensive digital-based devices. Ultra sound equipment, although increasingly portable, remains considerably more complex technologically and logistically and, of particular importance, more expensive. The main reason for not adopting ultrasound in the perioperative period other than its usage for vascular cannulation is lack of a standard training curriculum, fear of malpractices 
claim, difficulty in interpretation of life threatening perioperative complications and the expense of the equipment. The time however, is not far away when perioperative ultrasound will become a necessity rather than a luxury because of its numerous advantages and the fact that increasing marketing competition between ultrasound manufacturing companies will result in more advanced, portable and less expensive device. Ultrasonography is user dependent technology. As the usage extends, it is needed to ensure competence, define benefits of appropriate use, and limit unnecessary imaging and its consequences. It will be a disadvantage for the modern day anesthesiologist if they do not excel in learning the necessary skills which helps them in the interpretation of life threatening perioperative conditions using ultrasound techniques.

Financial support: None to declare

Conflicts of Interest: None to declare 


\section{REFERENCES}

1. Terkawi AS, Karakitsos D, Elbarbary M, Blaivas M, Durieux ME. Ultrasound for the anesthesiologists: present and future. ScientificWorldJournal. 2013 Nov 20;2013:683685 [PubMed][Free full text] doi: 10.1155/2013/683685.

2. CantyDJ,RoyseCF.Auditof anesthetistperformed echocardiography on perioperative management decisions for non-cardiac surgery. $\mathrm{Br} \mathrm{J}$ Anaesth. 2009;103:352-358 [PubMed]

3. Neal JM, Brull R, Chan VW, Grant SA, Horn JL, Liu SS, et al. The ASRA evidence-based medicine assessment of ultrasound-guided regional anesthesia and pain medicine: Executive summary. Reg Anesth Pain Med. 2010;35:S1-9. [PubMed] doi: 10.1097/AAP.0b013e3181d22fe0.

4. Koscielniak-Nielsen ZJ. Ultrasoundguided peripheral nerve blocks: what are the benefits? Acta Anaesthesiol Scand. 2008;52:727737. [PubMed] doi: 10.1111/j.13996576.2008.01666.x.

5. Rubin K, Sullivan D, Sadhasivam S. Are peripheral and neuraxial blocks with ultrasound guidance more effective and safe in children? Paediatr Anaesth. 2009;19:92-96. [PubMed] doi: 10.1111/j.14609592.2008.02918.x.

6. Perlas A, Chaparro LE, Chin KJ. Lumbar Neuraxial Ultrasound for Spinal and Epidural Anesthesia:
A Systematic Review and MetaAnalysis. Reg Anesth Pain Med. 2016 Mar-Apr;41(2):251-60. doi: 10.1097/ AAP.0000000000000184. [PubMed]

7. Brass P, Hellmich M, Kolodziej L, Schick G, Smith AF. Ultrasound guidance versus anatomical landmarks for internal jugular vein catheterization. Cochrane Database Syst Rev. 2015;1:CD011447. [PubMed][Free full text] doi: 10.1002/14651858. CD006962.pub2.

8. Lalu MM, Fayad A, Ahmed 0, Bryson GL, Fergusson DA, Barron CC, et al. Ultrasound-Guided Subclavian Vein Catheterization: A Systematic Review and Meta-Analysis. Crit Care Med. 2015;43:1498-1507 [PubMed] doi: 10.1097/CCM.0000000000000973.

9. Gu WJ, Tie HT, Liu JC, Zeng XT. Efficacy of ultrasound-guided radial artery catheterization: a systematic review and meta-analysis of randomized controlled trials. Crit Care. 2014;18:R93. [PubMed][Free full text] doi: $10.1186 /$ cc13862.

10. CantyDJ,RoyseCF. Auditofanesthetistperformed echocardiography on perioperative management decisions for non-cardiac surgery. Br J Anaesth. 2009;103:352-358. [PubMed]

11. Chou EH, Dickman E, Tsou PY, Tessaro M, Tsai YM, Ma MH, et al. Ultrasonography for confirmation of endotracheal tube placement: a systematic review and metaanalysis. Resuscitation. 2015;90:97103. [PubMed] doi: 10.1016/j. resuscitation.2015.02.013

12. Rudas M, Seppelt I. Safety and efficacy of ultrasonography before and during percutaneous dilatational tracheostomy in adult patients: a systematic review. Crit Care Resusc. 2012;14:297-301. [PubMed]

13. Van de Putte P, Perlas A. Ultrasound assessment of gastric content and volume. Br J Anaesth 2014;113:1222. [PubMed] doi: $10.1093 / \mathrm{bja} /$ aeu151.

14. Omar HR, Mangar D, Camporesi EM. Utilization of intraoperative transthoracic ultrasound for diagnosis of pneumothorax. Anesthesiology, 2012;116:967-68. [PubMed] doi: 10.1097/ALN.0b013e318249d0c3.

15. Via G, Hussain $A$, Wells $M$, Reardon $R$, ElBarbary $M$, Noble $V E$, et al. International evidence-based recommendations for focused cardiac ultrasound. J Am Soc Echocardiogr. 2014;27:683.e1-683.e33. [PubMed] doi: 10.1016/j.echo.2014.05.001.

16. Skubas NJ. Teaching whole body point-of-care ultrasound: advancing the skills of tomorrow's anesthesiologists. Anesthesiology. 2015;123(3):499-500. [PubMed] 